Crowe, J., Lumb, F.E., Harnett, M.M. and Harnett, W. (2017) Parasite excretory-secretory products and their effects on metabolic syndrome. Parasite Immunology, 39(5), e12410. (doi:10.1111/pim.12410)

There may be differences between this version and the published version. You are advised to consult the publisher's version if you wish to cite from it.

This is the peer-reviewed version of the following article: Crowe, J., Lumb, F.E., Harnett, M.M. and Harnett, W. (2017) Parasite excretorysecretory products and their effects on metabolic syndrome. Parasite Immunology, 39(5), e12410, which has been published in final form at 10.1111/pim.12410. This article may be used for non-commercial purposes in accordance with Wiley Terms and Conditions for SelfArchiving.

http://eprints.gla.ac.uk/134942/

Deposited on: 03 March 2017

Enlighten - Research publications by members of the University of Glasgow http://eprints.gla.ac.uk 
Received Date : 30-Sep-2016

Revised Date : 20-Dec-2016

Accepted Date : 05-Jan-2017

Article type : Commissioned Review or Article

\section{Parasite excretory-secretory products and their effects on metabolic syndrome}

Jenny Crowe ${ }^{1 *}$, Felicity E. Lumb ${ }^{2 *}$, Margaret M. Harnett ${ }^{1}$, William Harnett ${ }^{2+}$

${ }^{1}$ Institute of Infection, Immunity and Inflammation, Glasgow Biomedical Research Centre, University of Glasgow, G128TA, U.K. ${ }^{2}$ Strathclyde Institute of Pharmacy and Biomedical Sciences, University of Strathclyde, 161 Cathedral Street, Glasgow G4 0RE, U.K.

*These authors contributed jointly to this paper

+ Corresponding author:w.harnett@strath.ac.uk

Disclosures: None

\section{Abstract}

Obesity, one of the main causes of metabolic syndrome (MetS), is an increasingly common health and economic problem worldwide, and one of the major risk factors for developing type 2 diabetes and cardiovascular disease. Chronic, low-grade inflammation is associated with MetS and obesity. A dominant type 2/anti-inflammatory response is required for metabolic homeostasis within adipose tissue: during obesity, this response is replaced by

This article has been accepted for publication and undergone full peer review but has not been through the copyediting, typesetting, pagination and proofreading process, which may lead to differences between this version and the Version of Record. Please cite this article as doi: 10.1111/pim. 12410

This article is protected by copyright. All rights reserved. 
infiltrating, inflammatory macrophages and $\mathrm{T}$ cells. Helminths and certain protozoan parasites are able to manipulate the host immune response towards a $\mathrm{TH} 2$ immune phenotype that is beneficial for their survival and there is emerging data that there is an inverse correlation between the incidence of MetS and helminth infections, suggesting that, as with autoimmune and allergic diseases, helminths may play a protective role against MetS disease. Within this review, we will focus primarily on the excretory-secretory products that the parasites produce to modulate the immune system and discuss their potential use as therapeutics against MetS and its associated pathologies.

\section{Introduction}

Metabolic syndrome (MetS), which presents as a cluster of conditions such as hypertension, abdominal obesity, high fasting plasma glucose and dyslipidemia, is associated with a greater risk of developing type 2 diabetes (T2D) and cardiovascular diseases (CVD) such as atherosclerosis, the leading causes of mortality worldwide. The underlying mechanisms of MetS are still not fully understood but it is notable that the majority of patients with the syndrome exhibit some degree of insulin resistance (IR). There are many factors that contribute to the development of IR, including obesity, physical inactivity, age, diet and genetic factors, with obesity and physical inactivity being the main driving force in most cases. Thus, the mechanisms by which obesity may contribute to metabolic dysfunction have been under intense investigation in recent years. Hotamisligil et al were the first to observe a significant increase in the levels of the pro-inflammatory cytokine TNF- $\alpha$ in obese mice, thereby linking inflammatory responses to obesity ${ }^{1}$. Chronic inflammation has since been found to be strongly associated with obesity and MetS - obese people with MetS have an increased level of circulating inflammatory markers such as C-reactive protein ${ }^{2}$ and there is 
an increased incidence of cardiovascular diseases in patients with inflammatory diseases such as rheumatoid arthritis (RA) $)^{3}$. Under normal physiological circumstances, excess nutrients are processed and stored by professional metabolic tissues - the liver, white adipose tissue (WAT) and skeletal muscle. In obese individuals, these tissues can become overloaded, resulting in an increase in free fatty acids in the tissues and circulation, leading to cellular metabolic dysregulation manifesting as mitochondrial dysfunction, oxidative stress and an increase in intracellular lipids. Obesity-induced cellular dysfunction results in the activation of a number of intracellular signalling pathways such as those involving mTOR, JNK and IKK $\beta$. In turn, these pathways converge and inhibit insulin signalling, primarily via serine phosphorylation of insulin receptor substrate (IRS) proteins, blunting insulin action in these tissues and leading to $\mathrm{IR}^{4}$.

\section{Intracellular signalling pathways involved in obesity and MetS}

The signalling cascade of PI3K/AKT/mTOR has a profound influence on cell survival ${ }^{5}$, regulation of insulin sensitivity/resistance and cell metabolism ${ }^{6}$. Specifically, the recently demonstrated ability of the mTOR inhibitor, rapamycin, to prevent insulin resistance in humans $^{7}$ has highlighted this pathway as a point of intervention for MetS. The PI3K/AKT signalling cascade is activated by ligation of a range of receptors including $\mathrm{G}$ protein coupled receptors, $\mathrm{B}$ and $\mathrm{T}$ cell receptors and tyrosine kinase receptors such as the insulin and insulin like-growth factor 1 (IGF-1) receptor (Figure 1$)^{8}$. The last two receptors stimulate IRS1 and 2 to activate PI3K, which in turn results in the phosphorylation and activation of $\mathrm{Akt}^{9,10}$. In addition, the activation of the IIS (insulin/insulin like growth signalling) pathway leads to the up-regulation of mTOR complex 2 (mTORC2) and PDK1 activity, which are both required for the complete phosphorylation of $\mathrm{Akt}^{11}$. To date, Akt has been demonstrated to have 
multiple roles: regulating mTORC1 activation, mediating cell survival via the suppression of apoptosis-associated proteins such as $\mathrm{Bad}^{12}$, inhibiting Fox0 transcription ${ }^{13}$, and regulation of $\mathrm{NF}-\kappa \mathrm{B}$ activity ${ }^{14}$. Reflecting this, in the context of insulin signalling, the activation of Akt is essential for the upregulation of mTORC1 activity (via the inactivation of tuberous sclerosis complex 1 and $2(\mathrm{TSC} 1 / 2)$ and activation of S6 kinase (S6K) $)^{11}$. The mTOR complex is primarily conserved for nutrient sensing: thus, activation of mTOR can be mediated by environmental amino acids, fatty acids, glucose and hormones ${ }^{15}$, an important factor when one considers the mechanisms of insulin resistance (IR) in terms of MetS. Indeed, recent findings suggest that nutrition can impact on mTOR activation, demonstrating that calorie restriction can reduce activation of $\mathrm{mTOR}$ and prevent $\mathrm{IR}^{16}$. By contrast, a number of studies have demonstrated that over-activation of mTOR results in the formation of a negative feedback loop, whereby IRS-1 and IRS-2 are downregulated by S6K signalling ${ }^{17}$, thereby impairing insulin sensing. Thus, it is evident that mTOR deactivation is key to the control of IR and that nutrient/calorie restriction may have a role in regulating this.

The stress-activated c-Jun amino-terminal kinase (JNK) and the inhibitor of $\kappa$ kinase (IKK) are proposed to be central mediators of obesity-associated inflammation and stress responses (reviewed by ${ }^{18}$ ). Certainly, expression of both of these kinases is increased in the liver, skeletal muscle and adipose tissue of obese mice and genetic ablation of JNK1 renders mice resistant to weight gain and metabolic pathologies ${ }^{19}$. Additionally, mice that are heterozygous for IKK $\beta$, an upstream activator of $\mathrm{NF}-\mathrm{\kappa B}$, are protected from insulin resistance in both dietinduced and genetic obesity ${ }^{20}$. These kinases are potentially activated by a number of pathways during obesity. For example, signalling via the Toll-like receptors (TLRs) of the innate immune system potently activates JNK and IKK and TLRs have also been shown to be upregulated in adipose tissues during obesity. Indeed, macrophages and adipocytes can be 
activated to produce pro-inflammatory cytokines IL-6 and TNF- $\alpha$ after stimulation with saturated fatty acids (FAs) such as palmitate in a TLR4-dependent manner and knock-down of TLR4 reduces the activation of $N F-\kappa B$ in adipose tissue of obese mice ${ }^{21}$. Moreover, MyD88 is a key signalling adaptor molecule required by most TLRs that has also been shown to play a role in dysregulated signalling during obesity, as evidenced by targeted depletion of MyD88 in the CNS of mice protecting them from weight gain and leptin resistance ${ }^{22}$. Highlighting the role of TNF- $\alpha$ downstream of TLR signalling, Hotamisligil and colleagues ${ }^{1}$ have directly linked increased levels of TNF- $\alpha$ with insulin resistance and obesity whilst others ${ }^{23}$ have demonstrated that blockade of TNF- $\alpha$ signalling, via the genetic deletion of TNF- $\alpha$ and its two receptors TNFR1 and 2, reduces the incidence of IR in HFD-fed mice. This reflects that ligation of TNFR1 and 2 receptors can trigger the activation of MAPK and $\mathrm{NF \kappa B}$ signalling ${ }^{25}$, thereby promoting pro-inflammatory cytokine release $\mathrm{e}^{24}$ and indicating that, either via direct activity or synergistic mechanisms, the TLR pathway is likely to contribute to the pathogenesis associated with in metabolic syndrome.

Other innate immunity sensors like the NLRP3 (nucleotide-binding domain, leucine-richcontaining family, pyrin domain-containing-3) inflammasome, activation of which leads to the cleavage of pro-caspase- 1 and results in the production of mature IL- $1 \beta$ and IL-18, have also been demonstrated to play a critical role in the development of insulin resistance ${ }^{26}$. Thus, monocyte-derived macrophages from newly diagnosed, untreated type 2 diabetic patients show elevated expression of components of this inflammasome compared to healthy controls $^{27}$. Moreover, a high-fat diet was found to induce caspase-1 activation in the AT of mice $^{28}$, whilst ablation of NLRP3 improves insulin signalling in diet-induced obese mice and this is associated with a decrease in IL- $1 \beta$ in AT and reduced circulating IL- $18^{29,30}$. IL-1 $\beta$ is one of the main cytokines to be implicated in the development of insulin resistance and 
accordingly it has been shown that IL- $1 \beta^{-/-}$mice on a HFD do not exhibit $\mathrm{IR}^{30}$. Furthermore, saturated FAs such as palmitate and stearate, were shown to activate NLRP3 in macrophages in a ROS-dependent manner ${ }^{30}$. Collectively, this led to the proposal that the increased levels of glucose and fatty acids in the organs and circulation of obese individuals are recognised by the NLRP3 inflammasome as metabolic danger signals ${ }^{31}$. As the inflammasome can also be activated by molecules such as ceramides, ATP, oxidised LDL, uric acids and cholesterol crystals, all of which, along with FAs, are elevated in obesity and can increase ROS production, a prerequistite for NLRP3 signalling ${ }^{32}$, the NLRP3 inflammasome may be activated by a range of substances during obesity. Demonstrating the importance of NLRP3 activation in obesity, Dalmas and colleagues ${ }^{33}$ found that IL-1 $\beta$ derived from adipose tissue macrophages (ATMs) from obese type 2 diabetic patients induces the expression of IL-22 and IL-17 by adipose-resident $\mathrm{CD}^{+}{ }^{+} \mathrm{T}$ cells. These cytokines, in turn, can further stimulate the production of pro-IL-1 $\beta$ in macrophages ${ }^{33}$ highlighting the interplay between tissue resistant cells and indicating that the local cytokine milieu should be considered during the development of inflammasome-centric treatments. Nonetheless, these findings strongly support the NLRP3 inflammasome as an attractive therapeutic target against obesity and MetS, and indeed treatment with the IL-1 inhibitor Anakinra, has been shown to improve $\beta$ cell secretory functions and reduce systemic inflammatory markers CRP and IL-6 in T2D patients $^{34}$. Together, these studies demonstrate that there are multiple signalling pathways that are activated in times of nutrient excess that contribute to the inflammatory response in obesity and that targeting of these pathways can be beneficial when it comes to novel treatments for patients with MetS.

This article is protected by copyright. All rights reserved. 


\section{Cellular composition of adipose tissue during obesity}

Activation of these inflammatory pathways and consequent recruitment of infiltrating cells has a profound effect on the cellular composition of white adipose tissues (WAT). For example, in lean mice adipose ATMs are predominantly of an Alternatively Activated Macrophage (AAM)/M2-like tissue protective phenotype characterised by expression of Arginase 1, chitinase (Ym1) and IL-10 production. Whilst the transcription factor peroxisome

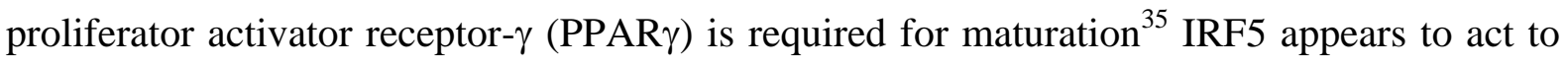
suppress accumulation of $\mathrm{AAM}$ in $\mathrm{AT}^{36}$ Inflammation during diet-induced obesity triggers adipocytes to secrete pro-inflammatory mediators such as IL-6, IL-1 $\beta$, TNF- $\alpha$, MIPs and

CCL-2 that recruit circulating macrophages into the tissue ${ }^{37,38}$, such that the number of macrophages in WAT positively correlates with increasing adiposity ${ }^{39}$. ATMs are known to play a key role in the inflammation associated with obesity. Although initially thought to be akin to M1-like inflammatory macrophages, a new subset of macrophages that lack expression of markers like CD38 and exhibit a distinct transcription profile, have recently been identified in adipose tissue and termed metabolically activated macrophages $(\mathrm{MMe})^{40}$. These macrophages can be differentiated in vitro via stimulation with insulin, glucose and palmitate, stimuli mimicking the conditions present during obesity. MMes express ABCA1 and CD36 and produce a host of pro-inflammatory cytokines and thus are phenotypically similar to ATMs found in human and murine adipose tissue ${ }^{40}$. Eosinophils have been demonstrated to be the major IL-4-producing cells in WAT and are essential for the maintenance of the AAM population in health ${ }^{41}$. In obesity, these cells are replaced by neutrophils and mast cells that help to generate the pro-inflammatory conditions in the WAT that are thought to contribute to IR. Additionally, it has recently been shown that the associated decrease in eosinophils in WAT is associated with a loss of group 2 innate 
lymphoid cells (ILC2s), that have been reported to be important for the production of the IL-5 and IL-13 that is required to sustain eosinophils and AAMs respectively in the WAT ${ }^{42}$. ILC2s have been detected in murine epididymal WAT and human subcutaneous fat and are decreased in both obese human donor adipose tissue and in the adipose tissue of mice fed a $\mathrm{HFD}^{43}$. By contrast, diet-induced obesity promotes the expansion of ILC1 cells that produce IFN- $\gamma$, driving differentiation of pro-inflammatory macrophages ${ }^{44}$. Other lymphocyte populations undergo similar shifts in phenotype: thus, whilst in healthy adipose tissue IL-4producing $\mathrm{TH} 2$ cells and adipose-specific $\mathrm{CD}^{+} \mathrm{FOXP}^{+} \mathrm{T}$ regulatory cells are essential for metabolic homeostasis, during diet-induced obesity these cells are replaced with infiltrating inflammatory $\mathrm{TH} 1$ cells ${ }^{45,46}$. Similarly, infiltrating cytotoxic $\mathrm{CD}^{+} \mathrm{T}$ cells have been demonstrated to arrive prior to M1 macrophages in adipose tissue and depletion of these cells results in reduced adipose inflammation and an improvement in glucose tolerance suggesting they may be pivotal in the initiation of inflammatory responses in obesity ${ }^{47}$. Studies utilising MHC Inull and MHC II ${ }^{\text {null }}$ mice revealed that B cells are crucial for the activation of $\mathrm{CD}^{+}$and $\mathrm{CD}^{+} \mathrm{T}$ cells in adipose tissue, and corresponding with this, B cell ${ }^{\text {null }}$ mice have improved insulin sensitivity when fed $\mathrm{HFD}^{48}$. However, adipose-specific IL-10-secreting B regulatory cells, recently identified by Nishimura $e t a l^{49}$, have been found to reduce inflammation within adipose tissues of obese mice. Consistent with this, depletion of IL-10 from B cells increased the infiltration of $\mathrm{M} 1$ cells and $\mathrm{CD}^{+} \mathrm{T}$ cells in adipose tissue and transfer of IL-10 Bregs, but not splenic B cells, from lean mice to obese B cell KO mice decreases the secretion of IFN- $\gamma$ from $\mathrm{CD}^{+} \mathrm{T}$ cells ${ }^{49}$. These studies suggest that, as with macrophages, there is a delicate balance of effector B and T cell subsets present in the AT that exert positive and negative effects on the immune response. Overall, it can be stated that a TH2-biased, antiinflammatory immune profile promotes metabolic homeostasis in AT.

This article is protected by copyright. All rights reserved. 


\section{Parasites and associated immune responses}

Helminths, and the products they produce, are the most potent natural inducers of a type- 2 immune response. They typically prime $\mathrm{T}$ cells towards a $\mathrm{TH} 2$ phenotype characterised by the production of IL-4, IL-5 and IL-13, increase tissue eosinophil numbers, and prime B cells to generate high levels of IgE. In addition, helminths bias macrophages towards an AAM/M2 phenotype and prime dendritic cells to induce TH2 responses. Helminths have co-evolved with humans for millennia and some are able to reside in individuals for decades without causing any severe pathology, which is beneficial not only to the parasite but also to the host. This is a result of their ability to modify the typical $\mathrm{TH} 2$ response with a regulatory component characterised by the presence of Breg and/or Treg cells, AAM/M2-like macrophages and the production of IL-10 and TGF- $\beta$ cytokines and IgG4 antibodies ${ }^{50}$. One of the key mechanisms utilised by helminths to induce this immune phenotype is the production of excretory-secretory (ES) products which interact with and influence their host's immune system ${ }^{51,52}$. However, in the past fifty years, due to increased hygiene and advancement of medicines we have drastically reduced the rate of infectious diseases such as those associated with helminths in the developed world. By contrast, during this time, the rate of allergic, autoimmune and inflammatory conditions such as asthma, rheumatoid arthritis and MetS-associated diseases has increased. In attempting to link these observations together it is pertinent that helminth infections and their products can be utilised in murine model systems to treat allergic and autoimmune diseases and currently there are number of clinical trials in progress, or being planned, that utilise helminths in the treatment of a range of allergic and autoimmune diseases (reviewed by ${ }^{53,54}$ ).

This article is protected by copyright. All rights reserved. 
Helminths are not alone in their ability to modulate the host immune response to create an optimum environment - protozoan parasites, such as Leishmania and Toxoplasma, are able to impair the host's initial TH1 response and bias it towards a TH2 phenotype to benefit their own survival. Specifically, L. mexicana, which causes the development of non-healing cutaneous lesions during infection, can suppress TH1-associated production of IL-12 ${ }^{55-57}$ by macrophages and DCs, and consequently can inhibit IFN- $\gamma$ production ${ }^{58}$. Further promoting this TH1-TH2 switch, products from the parasite can also significantly enhance IL-4 production in the draining $\mathrm{LN}^{59}$. In addition, there is growing evidence to suggest that other intracellular protozoans such as Toxoplasma, Plasmodium and Trypanosoma species may also be capable of skewing host production of TH1/TH2 associated cytokines. Reflecting this, a number of studies have demonstrated that infection with $P$. chabaudi or $T$. cruzi have protective effects in the murine model of multiple sclerosis (MS), experimental autoimmune encephalomyelitis (EAE), during which both parasites trigger the upregulation of IL-27 production, promoting a protective TH2 type phenotype ${ }^{60,61}$. To date, many of the mechanisms underpinning how these parasites manipulate the host cell machinery are yet to be defined. It is clear, however, that much like helminths, these intracellular parasites have evolved methods of steering the host immune response, possibly via the production of surface bound and/or excretory-secretory molecules.

As inflammation has now been established as a significant underlying mechanism of MetSassociated diseases it has recently been speculated that parasites may protect against MetS and this is supported by emerging evidence of an inverse correlation between helminth infections and incidence of $\mathrm{MetS}^{62}$. For example, Aravindhan et al examined the prevalence of filarial infection among diabetic, pre-diabetic and non-diabetic subjects in a cross-sectional study in India and reported a significant decrease in the incidence of filarial infection in 
diabetic patients compared to non-diabetic subjects ${ }^{63}$. Consistent with this, helminth infection has been shown to be effective at reducing weight gain and improving glucose tolerance in obese mice. For example, Yang et al used both a genetic deficiency and a diet-induced model of obesity to demonstrate that infection with the gastrointestinal nematode Nippostronglyus brasiliensis caused less weight gain than that observed in wild-type littermates or uninfected mice on high-fat diet (HFD) respectively ${ }^{64}$. Likewise, chronic infection with the trematode, Schistosoma mansoni, decreased fat mass and adipocyte hypertrophy in HFD-fed mice, which were accompanied by improvements in whole-body glucose tolerance and insulin sensitivity ${ }^{65}$. Recently, it has additionally been demonstrated that infection with the filarial nematode Litomosoides sigmodontis improves glucose tolerance in diet-induced obese mice, and this is associated with an increase in eosinophils, AAM and $\mathrm{CD}^{+} \mathrm{T}$ cells in the epididymal $\mathrm{AT}^{66}$. Furthermore, S. mansoni infection has been demonstrated to reduce atherosclerotic lesion development in $\mathrm{ApoE}^{-/-}$mice ${ }^{67,68}$, a well-established model for the study of atherosclerosic lesion formation ${ }^{69}$, and this is consistent with a reduced frequency of atherosclerosis in schistosomiasis patients ${ }^{67}$.

Perhaps providing a molecular rationale for this, it has also recently been demonstrated that parasites can directly affect the mTOR signalling pathway: Narasimhan et al found exposure of human monocyte-derived dendritic cells to Brugia malayi microfilarie (MF) to have a similar effect as treatment with Rapamycin in that it resulted in downregulation of phosphorylation of mTOR, p70S6K1 and 4EBP1 while also inducing autophagy in these cells, as evidenced by upregulation of phosphorylation of Beclin-1, induction of LC3II and degradation of $\mathrm{p} 62^{70}$. Similarly, it has been demonstrated that L. major promastigotes express a surface metalloprotease, GP63 that is important for mediating parasite engulfment ${ }^{71}$, and which influences a number of key signalling molecules ${ }^{72}$ in the intracellular environment of 
the macrophage. Most notably GP63 can inhibit mTORC1, consequently resulting in a blockade in phosphorylation of translational initiation factor 4E-BP1 ${ }^{73}$. This dephosphorylated state of 4E-BP1 causes suppression of macrophage protein synthesis ${ }^{74}$ and has been shown to be important for L. major parasite survival and replication. Moreover, it has been demonstrated that following infection, $L$. donovani-parasitised macrophages express lower levels of $\mathrm{AKT}^{75}$ which will have a profound downstream effect on mTORC1 activity. Indeed, the importance of mTOR activity in macrophages has recently been investigated, utilising macrophage specific mTOR null mice to demonstrate that in the absence of mTOR activity, HFD-fed mice exhibit a reduced liver and adipose inflammatory gene expression profile $^{76}$. These studies are of particular interest as very recent work has demonstrated that elevated dephosphorylated 4E-BP1 levels can protect against diet-induced obesity, insulin resistance and associated $\mathrm{MetS}^{77}$ while autophagy is known to play a key role in the suppression of production of inflammasome-associated cytokines IL-1 $\beta$ and IL-18 by stabilising mitochondria and preventing release of mitochondrial DNA into the cytoplasm ${ }^{78}$. As inhibition of the inflammasome or IL-1 $\beta$ has been demonstrated to prevent IR, targeting a regulator could represent a potential future therapy against diabetes and MetS.

Currently, there is a great deal of ongoing work examining the effect of helminth infection on metabolic syndrome: however, the present review will examine in detail the potential of parasite products, in particular, excretory secretory products, to influence the immune system, and specifically, their effect on the metabolic syndrome.

This article is protected by copyright. All rights reserved. 


\section{Excretory-secretory products of parasites}

Helminths are able to modulate the host immune response to ensure their own survival. One of the main mechanisms employed by these pathogens is the release of "excretory-secretory" (ES) products that actively dampen the host immune response to the parasite. These products are a diverse mix of proteins, glycans, lipids and nucleic acids and while they may utilise different mechanisms, in general they induce a type 2/regulatory phenotype in the host (see Table 1). ES-62, a $62 \mathrm{kDa}$ glycoprotein, is the major ES protein of the rodent filarial nematode Acanthocheilonema viteae and is perhaps the best characterised of all the secreted helminth products. ES-62 contains the unusual post-translational modification of phosphorylcholine (PC) moieties attached via an $N$-linked glycan ${ }^{79,80}$, and this feature appears to be responsible for the majority of the anti-inflammatory effects of ES- $62^{81,82}$. These effects include priming DCs towards a TH2 phenotype; inhibiting macrophage and mast cell activation; promoting induction of $\mathrm{B}$ regulatory cells and inhibiting TH1 and TH17 polarisation (reviewed in $^{83}$ ). Similarly, S. mansoni soluble egg antigen (SEA) which contains ES products, skews the host immune response to the worm from an inflammatory TH1 to a $\mathrm{TH} 2$ phenotype. DCs treated with SEA in vitro are polarised to prime $\mathrm{TH} 2$ responses and are refractory to TLR stimulation ${ }^{84}$ while macrophages treated with one of the components of SEA, LNFPIII, a trisaccharide LewisX-containing glycan, differentiate fully into an alternatively activated phenotype with upregulated expression of CD301, Ym1 and Arg1 and produce IL-10 ${ }^{85}$. In vivo administration of ES products is sufficient to induce a strong $\mathrm{TH} 2$ response - for example, ES from adult $N$. brasiliensis (NES) induces a strong TH2 response, even in the presence of the TH1/TH17 polarising agent, complete Freund's adjuvant ${ }^{86}$. Helminth ES products from a variety of species have also been found to be therapeutic in multiple mouse models of inflammatory disease including collagen-induced arthritis (CIA), 
type 1 diabetes (T1D), experimental autoimmune encephalomyelitis (EAE), colitis, and asthma and other allergies (reviewed $\mathrm{in}^{52}$ ). As discussed, MetS is associated with chronic inflammation and thus, given their potent anti-inflammatory effects, and therapeutic potential in inflammatory diseases it seems likely that helminth ES products could have a significant impact on MetS.

Protozoan parasites also produce a range of secreted products that influence the host to ensure their own survival. One of the best studied molecules constitutes a group of cysteine proteases (CPs) produced by L. mexicana ${ }^{87}$. It has been demonstrated that this highly active group of Cathepsin-L like proteases are primarily produced by the amastigote (intracellular form of parasite $)^{88}$ and their role as a key virulence factor during infection has been confirmed in a number of studies through the use of a variety of CP mutant promastigotes ${ }^{55}$. Further evidence suggests that the most abundantly expressed form of L. mexicana specific $\mathrm{CP}, \mathrm{CPB} 2.8$ can drive a $\mathrm{TH} 2$ response in vivo. Pollock et al have demonstrated that administration of purified recombinant CPB2.8 can stimulate both IL-4 and IL-5 production in the draining lymph node and can enhance circulating $\operatorname{IgE}$ titres ${ }^{59}$. The mechanisms underpinning these findings remain unclear, however it should be considered that, the CPs are similar in structure to other allergy-inducing proteases such as dust mite derived DerpI, a potent inducer of IL-4 and $\operatorname{IgE}^{89}$. Thus, it is perhaps unsurprising that CPB2.8 is so effective in polarising the immune response from a $\mathrm{TH} 1$ dominated healing response, to a $\mathrm{TH} 2$ dominated chronic phentotype. Hence, these Leishmania secreted CPs represent a group of potentially novel immunomodulatory molecules.

This article is protected by copyright. All rights reserved. 


\section{Helminth ES and MetS}

The strong TH2 response generated in response to SEA and LNFPIII led Bhargava et al to investigate whether these products have any effect on chronic inflammation with respect to obesity and subsequently improve metabolic function in HFD-fed mice. Injection of either for 4-6 weeks after the onset of obesity in HFD-mice augmented the production of IL-10, as well as increasing insulin sensitivity ${ }^{85}$. Unlike with live helminth infection ${ }^{65}$, neither treatment had any effect on body weight or circulating lipid or adiponectin concentrations ${ }^{85}$. However, both LNFPIII and SEA had significant effects on the cell composition/interactions in the WAT there was a decrease in the number of observed crown-like structures (CLS), and the gene expression of inflammatory genes such as $T N F-\alpha$, Caspl, $n l r p 3$, ill 18 and $i l 1 \beta$ was reduced with a corresponding increase in $i l 10$ and the M2 genes $\operatorname{Arg} 1$ and $M g L 1^{85}$. It has recently been demonstrated that SEA mediates this improvement in metabolic homeostasis by restoring the type 2 response in the WAT through the induction of eosinophil recruitment ${ }^{65}$, which has previously been shown to be crucial in promoting the presence of M2 macrophages $^{41}$. Correspondingly, SEA shifts the M1/M2 ratio towards an M2 phenotype, and increased the numbers of IL- $4^{+}, \mathrm{IL}^{-} 5^{+}$and $\mathrm{IL}-13^{+} \mathrm{CD} 4^{+} \mathrm{T}$ cells in gonadal $\mathrm{WAT}^{65}$. In keeping with improved insulin sensitivity there was also an increase in insulin receptor B, insulin receptor substrate 2, C/ebp- $\alpha$ and glucose transporter 4 gene expression in the WAT of LNFPIII-treated mice. These effects are not due to direct effects of LNFPIII on adipocytes: they appear to be mediated indirectly via production of IL-10 by macrophages as conditioned medium from LNFPIII-primed macrophages from WT but not IL-10 $-^{-}$mice improved insulin responsiveness in 3T3-11 adipocytes ${ }^{85}$. SEA and LNFPIII were also demonstrated to have a strong protective effect on diet-induced hepatic steatosis, with treated HFD-mice exhibiting 
reduced serum levels of the triglycerides, AST and ALT as well as decreases in genes associated with lipogenesis such as Srebp, in the liver ${ }^{85}$.

Of interest, while not a secreted helminth product, L. sigmodontis antigen (LsAg) has also been demonstrated to mediate some protection against MetS, as therapeutic administration of LsAg for a two-week period improves glucose tolerance in diet-induced obese mice. This protection was found to require eosinophils but to be independent of $\mathrm{CD}^{+} \mathrm{FOXP}^{+} \mathrm{T}$ cells ${ }^{66}$. Treatment of the pre-adipocyte cell line (3T3-L1) with LsAg was found to inhibit their differentiation into mature adipocytes suggesting LsAg may also be able to suppress adipogenesis $^{66}$. It will therefore be interesting to see whether Ls ES products have similar properties.

\section{Helminth ES and Atherosclerosis}

Atherosclerosis is a lipid-driven disease of the arteries, caused by lipid deposition and intimal thickening of the aorta and larger arteries, characterised by sustained inflammatory responses and specifically, the chronic activation of macrophages ${ }^{90,91}$. MetS significantly increases the risk of atherosclerosis, which is one of the main underlying pathologies for cardiovascular diseases such as stroke and myocardial infarctions, as alluded to earlier, the leading cause of death in the Western world ${ }^{92}$. Wolfs et al demonstrated that weekly treatment with SEA resulted in a $44 \%$ reduction in atherosclerotic plaque size in a cholesterol-induced murine model of atherosclerosis ${ }^{91}$. This was associated with a significant decrease in circulating inflammatory monocytes, as well as reduced plaque necrosis and inflammation, and reduced gene expression of CD68, TNF- $\alpha$ and MCP-1 in the aortic $\operatorname{arch}^{91}$. Chronic exposure to SEA has also been shown to cause a $30 \%$ reduction in plasma serum cholesterol and LDL levels in $\mathrm{ApoE}^{-/-}$mice fed a high-fat $\operatorname{diet}^{93}$, however there was no effect on lesion size or 
inflammation, a perhaps surprising observation which the authors speculated could be a result of using dead eggs and heat-treated SEA in this study ${ }^{93}$.

ES-62's anti-inflammatory properties dictate that it can protect against inflammatory diseases in models such as collagen-induced arthritis and the MRL/lpr model of systemic lupus erythematosus $^{94-96}$. Patients with these diseases are at greater risk of developing atherosclerosis and thus the protective effect of ES-62 was investigated in gld.ApoE ${ }^{-/-}$mice, that are commonly utilised as a model for the study of the accelerated cardiovascular disease that can occur in some lupus patients ${ }^{97}$. When treated with ES-62, via osmotic pumps for 12 weeks to release ES-62 at a steady rate and mimic natural infection, these mice demonstrated reduced atherosclerotic lesion area of nearly $60 \%$ compared to PBS-treated mice, with reduced numbers of macrophages and collagen at the lesion site. Similar to studies in the MRL/lpr mouse, they also had some evidence of reduced renal disease as measured by decreased proteinuria, as well as decreased levels of the anti-nuclear antibodies (ANA) that contribute to kidney disease ${ }^{98}$.

\section{Can other parasite molecules influence the outcome of MetS?}

The seminal work carried out by Bhargava (2012) has shown that modulation of inflammatory responses by a parasite-derived product can significantly impact on the outcome of MetS in obese mice ${ }^{85}$. Specifically, it has been shown that suppression of M1 inflammatory responses and polarization towards an M2 phenotype are advantageous in the fight against metabolic disease, therefore suggesting the parasite products that influence M1/M2 polarisation during chronic parasite infection may provide a potential novel therapy for treatment or prevention of MetS. It is interesting to speculate therefore that other parasite 
products with the ability to influence the differentiation of macrophages may also have the potential to be therapeutic in MetS. With this is mind, it is of particular interest that the intracellular protozoan $T$. gondii, has been shown to utilise some of its key proteins conserved for cellular invasion to do just that. Rhoptry proteins (ROPs) are secreted from the apical complex during the process of host cell entry and are either released into the host cytosol or retained at the parasitophorous vacuole membrane (PVM). Recently, a number of studies have demonstrated how ROPs, specifically ROP16 (in Type I/III strains of $T$. gondii) can target host transcription and cause prolonged phosphorylation of STAT3 and STAT6, resulting in the suppression of IL-12 production $^{99,100}$. Further to this, ROP16-mediated STAT6 activation has also been associated with enhanced levels of arginase-1 production, in both macrophages and fibroblasts. Thus, the secreted ROP16 appears to be instrumental in ablating TH2 suppressive cytokine production and also promoting M2 macrophage polarization $^{101}$. Moreover, ROPs do not appear to be the only protozoan products to exhibit this effect: for example, a T. gondii-specific peroxiredoxin (Prx) known as $\operatorname{TgPRx}^{102}$, which has recently been shown to be a potent anti-inflammatory molecule ${ }^{103}$, appears to promote development of an AAM phenotype via STAT6-dependent and -independent enhancement of arginase-1 and YM1 expression. In addition, the recombinant protein has been shown to stimulate the expression of IL-10 to further reinforce the regulatory/TH2 type response.

These marked effects of the protozoan Prx may not be so surprising as a number of studies had previously demonstrated the effectiveness of Prxs derived from the helminths $S$. mansoni and Fasciola hepatica, in similarly driving alternative activation of macrophages in vivo. Thus, treatment of BALB/c mice with recombinant $F$. hepatica Prx, induces Ym1 expression in peritoneal macrophages, and increases circulating titres of IL- $4^{104,105}$. Additionally, as mentioned previously, various ES products from several helminth species stimulate alternatively activated macrophages: thus, ES-62-treated macrophages are refractory to LPS-

This article is protected by copyright. All rights reserved. 
induced pro-inflammatory cytokine production ${ }^{106}$ and treatment of macrophages with SEA induces an anti-inflammatory profile with decreased levels of LPS-induced IL-12 and TNF- $\alpha$ and increased IL-10 production $^{91}$.

\section{Targeting other relevant inflammatory mediators}

It has recently been demonstrated that ES-62 interacts, via its PC moieties, with CRP in human serum ${ }^{107}$. This interaction does not result in activation of the complement cascade because the ES-62-CRP-C1q complex generated appears to be unable to efficiently cleave $\mathrm{C} 2$. In this way ES-62 secreted by the parasite during infection can provide some protection against the activation of complement, thus preventing parasite opsonisation. However, it also further demonstrates the ability of ES-62 to dampen inflammatory responses, in this case CRP-dependent that may play an important role in conditions that represent medical emergencies such as myocardial infarction and stroke. Furthermore, PC binding to CRP has recently been demonstrated to bias migrating monocytes and T cells towards an M2 and TH2 phenotype respectively in an in vitro model ${ }^{108}$ and therefore it is possible that ES-62 by binding to CRP may also have this capability.

We have previously discussed the importance of NLRP3 inflammasome activation in driving inflammation and disease during MetS and therefore, molecules with the ability to suppress such responses could provide a potential therapeutic for the syndrome. For example, treatment of human macrophages with $F$. hepatica helminth defence molecule 1 (FhHDM-1), a cathelicidin-like molecule secreted by the parasite, significantly reduces their production of IL-1 $\beta$ in response to phagocytosis of Alum particles ${ }^{109}$ while a small molecule analogue (SMA) of ES-62 (based on its PC moiety), SMA 12b, has been found to mediate its 
protective effects in the CIA model via suppression of NLRP3 activation and decreased IL$1 \beta$ production $^{110}$. The protozoan product rTfPRx suppresses macrophage ROS production via modulation of NLRP3 inflammasome activation and is capable of inhibiting both caspase-1 and IL-1 $\beta$ production following LPS-stimulation of the inflammasome ${ }^{103}$. Finally, Leishmania-derived, GP63 also appears to modulate activation of the NLRP3 inflammasome, suppressing the production of IL- $1 \beta$, both during infection and, importantly, in macrophages treated with purified GP6 ${ }^{111}$. These modulators all exhibit potential as modifiers of the NLRP3 inflammasome pathway and as such are exciting candidates for the basis of future therapeutics.

As mentioned earlier in the review, MyD88 appears to be a crucial integrator of TLR and inflammasome signals impacting on obesity and $\mathrm{MetS}^{112}$, and one of the key mechanisms of ES-62 in its protection in CIA and lupus models is the degradation of MyD88 ${ }^{95,96}$. Interestingly, ES-62 has also been demonstrated to strongly suppress the basal levels of active Akt in DCs in vitro in a TLR4-dependent manner $^{81}$ thus suggesting that it can target multiple layers of the pathways necessary to reduce the damaging pro-inflammatory immune response generated during MetS.

\section{Conclusions}

Inflammation associated with MetS has now been established to be central to the development of insulin resistance and cardiovascular disease. During obesity, the cellular composition of adipose tissue changes from an anti-inflammatory/TH2 environment characterised by $\mathrm{M} 2$, eosinophils, $\mathrm{TH} 2 \mathrm{CD}^{+} \mathrm{T}$ cells and Bregs to a pro-inflammatory environment characterised by higher numbers of M1, neutrophils, mast cells, TH1 and 
cytotoxic $\mathrm{CD}^{+} \mathrm{T}$ cells. Throughout this review we have discussed the host immune regulation that helminths and protozoans can elicit during infection and the secretory molecules that these parasites use to exert these effects, particularly their ability to drive a TH2 response while suppressing an opposing inflammatory phenotype. Therefore, it is possible that helminth- and protozoan-derived molecules that enhance protective antiinflammatory responses, such as Type 2 immunity, alternative activation of macrophages and modulation of mTOR signalling could be beneficial in the treatment of metabolic disorders (Figure 2).

References

1. Hotamisligil GS, Shargill NS, Spiegelman BM. Adipose expression of tumor necrosis factor-alpha: direct role in obesity-linked insulin resistance. Science. 1993;259(5091):87-91. doi:10.1126/science.7678183.

2. Van Guilder GP, Hoetzer GL, Greiner JJ, Stauffer BL, DeSouza CA. Influence of Metabolic Syndrome on Biomarkers of Oxidative Stress and Inflammation in Obese Adults. Obesity. 2006;14(12):2127-2131. doi:10.1038/oby.2006.248.

3. Ong KL, Wu BJ, Cheung BMY, Barter PJ, Rye K-A. Arthritis: its prevalence, risk factors, and association with cardiovascular diseases in the United States, 1999 to 2008. Ann Epidemiol. 2013;23(2):80-86. doi:10.1016/j.annepidem.2012.11.008.

4. Odegaard JI, Chawla A. Pleiotropic Actions of Insulin Resistance and Inflammation in Metabolic Homeostasis. Science. 2013;339(6116):172-177. doi:10.1126/science.1230721.

5. Datta SR, Brunet A, Greenberg ME. Cellular survival: a play in three Akts. Genes Dev. 1999;13(22):2905-2927.

6. Franke TF. Intracellular signaling by Akt: bound to be specific. Sci Signal. 2008.

7. Krebs M, Brunmair B, Brehm A, et al. The Mammalian target of rapamycin pathway regulates nutrient-sensitive glucose uptake in man. Diabetes. 2007;56(6):1600-1607.

8. White MF. Insulin signaling in health and disease. Science. 2003.

9. Valentinis B, Baserga $\mathrm{R}$. IGF-I receptor signalling in transformation and differentiation. J Clin Pathol. 2001.

10. Fingar DC, Blenis J. Target of rapamycin (TOR): an integrator of nutrient and growth factor signals and coordinator of cell growth and cell cycle progression. Oncogene. 2004;23(18):3151-3171.

This article is protected by copyright. All rights reserved. 
11. Sarbassov DD, Guertin DA, Ali SM, Sabatini DM. Phosphorylation and regulation of Akt/PKB by the rictor-mTOR complex. Science. 2005;307(5712):1098-1101.

12. Datta SR, Dudek H, Tao X, et al. Akt phosphorylation of BAD couples survival signals to the cell-intrinsic death machinery. CELL. 1997;91(2):231-241.

13. Zhang X, Tang N, Hadden TJ, Rishi AK. Akt, FoxO and regulation of apoptosis. Biochim Biophys Acta Ldots. 2011.

14. Dan HC, Cooper MJ, Cogswell PC, Duncan JA, Ting JP-Y, Baldwin AS. Aktdependent regulation of NF-KB is controlled by mTOR and Raptor in association with IKK. Genes Dev. 2008;22(11):1490-1500. doi:10.1101/gad.1662308.

15. Tremblay F, Marette A. Amino acid and insulin signaling via the mTOR/p70 S6 kinase pathway. A negative feedback mechanism leading to insulin resistance in skeletal muscle cells. J Biol Chem. 2001;276(41):38052-38060.

16. Blagosklonny MV. Linking calorie restriction to longevity through sirtuins and autophagy: any role for TOR. Cell Death Dis. 2010;1:e12-e12.

17. Shah OJ, Wang Z, Hunter T. Inappropriate activation of the TSC/Rheb/mTOR/S6K cassette induces IRS1/2 depletion, insulin resistance, and cell survival deficiencies. Curr Biol CB. 2004;14(18):1650-1656.

18. Gregor MF, Hotamisligil GS. Inflammatory Mechanisms in Obesity. Annu Rev Immunol. 2011;29(1):415-445. doi:10.1146/annurev-immunol-031210-101322.

19. Hirosumi J, Tuncman G, Chang L, et al. A central role for JNK in obesity and insulin resistance. Nature. 2002;420(6913):333-336. doi:10.1038/nature01137.

20. Yuan M, Konstantopoulos N, Lee J, et al. Reversal of Obesity- and Diet-Induced Insulin Resistance with Salicylates or Targeted Disruption of Ikk $\beta$. Science. 2001;293(5535):1673-1677. doi:10.1126/science.1061620.

21. Shi H, Kokoeva MV, Inouye K, Tzameli I, Yin H, Flier JS. TLR4 links innate immunity and fatty acid-induced insulin resistance. J Clin Invest. 2006;116(11):3015-3025. doi:10.1172/JCl28898.

22. Kleinridders A, Schenten D, Könner AC, et al. MyD88 Signaling in the CNS Is Required for Development of Fatty Acid-Induced Leptin Resistance and Diet-Induced Obesity. Cell Metab. 2009;10(4):249-259. doi:10.1016/j.cmet.2009.08.013.

23. Uysal KT, Wiesbrock SM, Marino MW, Hotamisligil GS. Protection from obesityinduced insulin resistance in mice lacking TNF- $\alpha$ function. Nature. 1997;389(6651):610-614. doi:10.1038/39335.

24. Parameswaran N, Patial S. Tumor Necrosis Factor- $\alpha$ Signaling in Macrophages. Crit Rev Eukaryot Gene Expr. 2010;20(2):87-103.

25. Illei GG, Lipsky PE. Novel, non-antigen-specific therapeutic approaches to autoimmune/inflammatory diseases. Curr Opin Immunol. 2000;12(6):712-718. doi:10.1016/S0952-7915(00)00167-9.

26. Schroder K, Zhou R, Tschopp J. The NLRP3 Inflammasome: A Sensor for Metabolic Danger? Science. 2010;327(5963):296-300. doi:10.1126/science.1184003.

This article is protected by copyright. All rights reserved. 
27. Lee H-M, Kim J-J, Kim HJ, Shong M, Ku BJ, Jo E-K. Upregulated NLRP3 Inflammasome Activation in Patients With Type 2 Diabetes. Diabetes. 2013;62(1):194204. doi:10.2337/db12-0420.

28. Stienstra R, Joosten LAB, Koenen $T$, et al. The Inflammasome-Mediated Caspase-1 Activation Controls Adipocyte Differentiation and Insulin Sensitivity. Cell Metab. 2010;12(6):593-605. doi:10.1016/j.cmet.2010.11.011.

29. Vandanmagsar B, Youm $\mathrm{Y}-\mathrm{H}$, Ravussin A, et al. The NLRP3 inflammasome instigates obesity-induced inflammation and insulin resistance. Nat Med. 2011;17(2):179-188. doi:10.1038/nm.2279.

30. Wen H, Gris D, Lei $\mathrm{Y}$, et al. Fatty acid-induced NLRP3-ASC inflammasome activation interferes with insulin signaling. Nat Immunol. 2011;12(5):408-415. doi:10.1038/ni.2022.

31. Haneklaus M, O'Neill LAJ. NLRP3 at the interface of metabolism and inflammation. Immunol Rev. 2015;265(1):53-62. doi:10.1111/imr.12285.

32. Tanti J-F, Ceppo F, Jager J, Berthou F. Implication of inflammatory signaling pathways in obesity-induced insulin resistance. Front Endocrinol. 2013;3. doi:10.3389/fendo.2012.00181.

33. Dalmas E, Venteclef N, Caer C, et al. T Cell-Derived IL-22 Amplifies IL-1 $\beta$-Driven Inflammation in Human Adipose Tissue: Relevance to Obesity and Type 2 Diabetes. Diabetes. 2014;63(6):1966-1977. doi:10.2337/db13-1511.

34. Larsen $\mathrm{CM}$, Faulenbach $\mathrm{M}$, Vaag $\mathrm{A}$, et al. Interleukin-1-receptor antagonist in type 2 diabetes mellitus. $N$ Engl $J$ Med. 2007;356(15):1517-1526. doi:10.1056/NEJMoa065213.

35. Odegaard JI, Ricardo-Gonzalez RR, Goforth MH, et al. Macrophage-specific PPARY controls alternative activation and improves insulin resistance. Nature. 2007;447(7148):1116-1120. doi:10.1038/nature05894.

36. Dalmas E, Toubal A, Alzaid F, et al. Irf5 deficiency in macrophages promotes beneficial adipose tissue expansion and insulin sensitivity during obesity. Nat Med. 2015;21(6):610-618. doi:10.1038/nm.3829.

37. $\mathrm{Xu} \mathrm{H}$, Barnes GT, Yang Q, et al. Chronic inflammation in fat plays a crucial role in the development of obesity-related insulin resistance. J Clin Invest. 2003;112(12):18211830. doi:10.1172/JCl200319451.

38. Lumeng CN, Bodzin JL, Saltiel AR. Obesity induces a phenotypic switch in adipose tissue macrophage polarization. J Clin Invest. 2007;117(1):175-184. doi:10.1172/JCl29881.

39. Weisberg SP, McCann D, Desai M, Rosenbaum M, Leibel RL, Ferrante AW. Obesity is associated with macrophage accumulation in adipose tissue. J Clin Invest. 2003;112(12):1796-1808. doi:10.1172/JCI200319246.

40. Kratz M, Coats BR, Hisert KB, et al. Metabolic dysfunction drives a mechanistically distinct proinflammatory phenotype in adipose tissue macrophages. Cell Metab. 2014;20(4):614-625. doi:10.1016/j.cmet.2014.08.010.

This article is protected by copyright. All rights reserved. 
41. Wu D, Molofsky AB, Liang H-E, et al. Eosinophils Sustain Adipose Alternatively Activated Macrophages Associated with Glucose Homeostasis. Science. 2011;332(6026):243-247. doi:10.1126/science.1201475.

42. Molofsky $A B$, Nussbaum JC, Liang H-E, et al. Innate lymphoid type 2 cells sustain visceral adipose tissue eosinophils and alternatively activated macrophages. $J$ Exp Med. 2013;210(3):535-549. doi:10.1084/jem.20121964.

43. Brestoff JR, Kim BS, Saenz SA, et al. Group 2 innate lymphoid cells promote beiging of white adipose tissue and limit obesity. Nature. 2015;519(7542):242-246. doi:10.1038/nature14115.

44. O'Sullivan TE, Rapp M, Fan X, et al. Adipose-Resident Group 1 Innate Lymphoid Cells Promote Obesity-Associated Insulin Resistance. Immunity. 2016;45(2):428-441. doi:10.1016/j.immuni.2016.06.016.

45. Winer S, Chan Y, Paltser G, et al. Normalization of Obesity-Associated Insulin Resistance through Immunotherapy: CD4+ T Cells Control Glucose Homeostasis. Nat Med. 2009;15(8):921-929. doi:10.1038/nm.2001.

46. Strissel KJ, DeFuria J, Shaul ME, Bennett G, Greenberg AS, Obin MS. T-Cell Recruitment and Th1 Polarization in Adipose Tissue During Diet-Induced Obesity in C57BL/6 Mice. Obesity. 2010;18(10):1918-1925. doi:10.1038/oby.2010.1.

47. Nishimura S, Manabe I, Nagasaki M, et al. CD8+ effector T cells contribute to macrophage recruitment and adipose tissue inflammation in obesity. Nat Med. 2009;15(8):914-920. doi:10.1038/nm.1964.

48. Winer DA, Winer $S$, Shen $\mathrm{L}$, et al. B cells promote insulin resistance through modulation of $\mathrm{T}$ cells and production of pathogenic $\lg \mathrm{G}$ antibodies. Nat Med. 2011;17(5):610-617. doi:10.1038/nm.2353.

49. Nishimura S, Manabe I, Takaki S, et al. Adipose Natural Regulatory B Cells Negatively Control Adipose Tissue Inflammation. Cell Metab. 2013;18(5):759-766. doi:10.1016/j.cmet.2013.09.017.

50. Maizels RM, Yazdanbakhsh M. Immune Regulation by helminth parasites: cellular and molecular mechanisms. Nat Rev Immunol. 2003;3(9):733-744. doi:10.1038/nri1183.

51. Hewitson JP, Grainger JR, Maizels RM. Helminth immunoregulation: The role of parasite secreted proteins in modulating host immunity. Mol Biochem Parasitol. 2009;167(1-9):1-11. doi:10.1016/j.molbiopara.2009.04.008.

52. Harnett W. Secretory products of helminth parasites as immunomodulators. Mol Biochem Parasitol. 2014;195(2):130-136. doi:10.1016/j.molbiopara.2014.03.007.

53. Versini M, Jeandel P-Y, Bashi T, Bizzaro G, Blank M, Shoenfeld Y. Unraveling the Hygiene Hypothesis of helminthes and autoimmunity: origins, pathophysiology, and clinical applications. BMC Med. 2015;13:81. doi:10.1186/s12916-015-0306-7.

54. Harnett W, Harnett MM. Helminth-derived immunomodulators: can understanding the worm produce the pill? Nat Rev Immunol. 2010;10(4):278-284. doi:10.1038/nri2730.

55. Cameron P, McGachy A, Anderson M, et al. Inhibition of Lipopolysaccharide-Induced Macrophage IL-12 Production by Leishmania mexicana Amastigotes: The Role of

This article is protected by copyright. All rights reserved. 
Cysteine Peptidases and the NF- B Signaling Pathway. J Immunol. 2004;173(5):3297-3304.

56. Shweash M, Adrienne McGachy H, Schroeder J, et al. Leishmania mexicana promastigotes inhibit macrophage IL-12 production via TLR-4 dependent COX-2, iNOS and arginase-1 expression. Mol Immunol. 2011;48(15-16):1800-1808. doi:10.1016/j.molimm.2011.05.013.

57. Contreras I, Estrada JA, Guak $\mathrm{H}$, et al. Impact of Leishmania mexicana infection on dendritic cell signaling and functions. PLoS Negl Trop Dis. 2014;8(9):e3202.

58. Rodriguez-Sosa M, Monteforte GM, Satoskar AR. Susceptibility to Leishmania mexicana infection is due to the inability to produce IL-12 rather than lack of IL-12 responsiveness. Immunol Cell Biol. 2001;79(4):320-322.

59. Pollock KGJ, McNeil KS, Mottram JC, et al. The Leishmania mexicana Cysteine Protease, CPB2.8, Induces Potent Th2 Responses. J Immunol. 2003;170(4):17461753.

60. Farias AS, Talaisys RL, Blanco YC, Lopes S. Regulatory $\mathrm{T}$ cell induction during Plasmodium chabaudi infection modifies the clinical course of experimental autoimmune encephalomyelitis. PLoS Ldots. 2011.

61. Tadokoro CE, Vallochi AL, Rios LS, et al. Experimental autoimmune encephalomyelitis can be prevented and cured by infection with Trypanosoma cruzi. $J$ Autoimmun. 2004;23(2):103-115.

62. Wiria AE, Djuardi $Y$, Supali T, Sartono E, Yazdanbakhsh M. Helminth infection in populations undergoing epidemiological transition: a friend or foe? Semin Immunopathol. 2012;34(6):889-901. doi:10.1007/s00281-012-0358-0.

63. Aravindhan V, Mohan V, Surendar J, et al. Decreased prevalence of lymphatic filariasis among subjects with type-1 diabetes. Am J Trop Med Hyg. 2010;83(6):13361339. doi:10.4269/ajtmh.2010.10-0410.

64. Yang Z, Grinchuk V, Smith A, et al. Parasitic Nematode-Induced Modulation of Body Weight and Associated Metabolic Dysfunction in Mouse Models of Obesity. Infect Immun. 2013;81(6):1905-1914. doi:10.1128/IAI.00053-13.

65. Hussaarts L, García-Tardón N, Beek L van, et al. Chronic helminth infection and helminth-derived egg antigens promote adipose tissue M2 macrophages and improve insulin sensitivity in obese mice. FASEB J. 2015;29(7):3027-3039. doi:10.1096/fj.14266239.

66. Berbudi A, Surendar J, Ajendra J, et al. Filarial Infection or Antigen Administration Improves Glucose Tolerance in Diet-Induced Obese Mice. J Innate Immun. 2016;8(6). doi:10.1159/000448401.

67. Doenhoff MJ, Stanley RG, Griffiths K, Jackson CL. An anti-atherogenic effect of Schistosoma mansoni infections in mice associated with a parasite-induced lowering of blood total cholesterol. Parasitology. 2002;125(5):415-421. doi:10.1017/S0031182002002275.

This article is protected by copyright. All rights reserved. 
68. Stanley RG, Jackson CL, Griffiths K, Doenhoff MJ. Effects of Schistosoma mansoni worms and eggs on circulating cholesterol and liver lipids in mice. Atherosclerosis. 2009;207(1):131-138. doi:10.1016/j.atherosclerosis.2009.04.037.

69. Plump AS, Smith JD, Hayek $T$, et al. Severe hypercholesterolemia and atherosclerosis in apolipoprotein E-deficient mice created by homologous recombination in ES cells. Cell. 1992;71(2):343-353. doi:10.1016/00928674(92)90362-G.

70. Narasimhan PB, Bennuru S, Meng Z, et al. Microfilariae of Brugia malayi Inhibit the mTOR Pathway and Induce Autophagy in Human Dendritic Cells. Infect Immun. 2016;84(9):2463-2472. doi:10.1128/IAI.00174-16.

71. Brittingham A, Morrison CJ, McMaster WR, McGwire BS, Chang KP, Mosser DM. Role of the Leishmania surface protease gp63 in complement fixation, cell adhesion, and resistance to complement-mediated lysis. J Immunol Baltim Md 1950. 1995;155(6):3102-3111.

72. Isnard A, Shio MT, Olivier M. Impact of Leishmania metalloprotease GP63 on macrophage signaling. Front Cell Infect Microbiol. 2012;2. doi:10.3389/fcimb.2012.00072.

73. Jaramillo M, Gomez MA, Larsson O, et al. Leishmania Repression of Host Translation through mTOR Cleavage Is Requiredfor Parasite Survival and Infection. Cell Host Microbe. 2011;9(4):331-341.

74. Gingras A-C, Kennedy SG, O'Leary MA, Sonenberg N, Hay N. 4E-BP1, a repressor of mRNA translation, is phosphorylated and inactivated by the Akt(PKB) signaling pathway. Genes Dev. 1998;12(4):502-513.

75. Dey R, Majumder N, Bhattacharjee S. Leishmania donovani-induced ceramide as the key mediator of Akt dephosphorylation in murine macrophages: role of protein kinase $\mathrm{C \zeta}$ and phosphatase. Infect Ldots. 2007.

76. Jiang $H$, Westerterp $M$, Wang $C$, Zhu $Y$, Ai D. Macrophage mTORC1 disruption reduces inflammation and insulin resistance in obese mice. Diabetologia. 2014;57(11):2393-2404. doi:10.1007/s00125-014-3350-5.

77. Tsai S-Y, Rodriguez AA, Dastidar SG, et al. Increased 4E-BP1 Expression Protects against Diet-Induced Obesity and Insulin Resistance in Male Mice. Cell Rep. 2016;16(7):1903-1914. doi:10.1016/j.celrep.2016.07.029.

78. Nakahira K, Haspel JA, Rathinam VA, et al. Autophagy proteins regulate innate immune response by inhibiting NALP3 inflammasome-mediated mitochondrial DNA release. Nat Immunol. 2011;12(3):222-230. doi:10.1038/ni.1980.

79. Harnett W, Houston KM, Amess R, Worms MJ. Acanthocheilonema viteae: Phosphorylcholine Is Attached to the Major Excretory-Secretory Product via an NLinked Glycan. Exp Parasitol. 1993;77(4):498-502. doi:10.1006/expr.1993.1113.

80. Haslam SM, Khoo K-H, Houston KM, Harnett W, Morris HR, Dell A. Characterisation of the phosphorylcholine-containing $\mathrm{N}$-linked oligosaccharides in the excretorysecretory $62 \mathrm{kDa}$ glycoprotein of Acanthocheilonema viteae. Mol Biochem Parasitol. 1997;85(1):53-66. doi:10.1016/S0166-6851(96)02807-1.

This article is protected by copyright. All rights reserved. 
81. Goodridge HS, McGUINESS S, Houston KM, et al. Phosphorylcholine mimics the effects of ES-62 on macrophages and dendritic cells. Parasite Immunol. 2007;29(3):127-137. doi:10.1111/j.1365-3024.2006.00926.x.

82. Harnett MM, Kean DE, Boitelle A, et al. The phosphorycholine moiety of the filarial nematode immunomodulator ES-62 is responsible for its anti-inflammatory action in arthritis. Ann Rheum Dis. 2008;67(4):518-523. doi:10.1136/ard.2007.073502.

83. Pineda MA, Lumb F, Harnett MM, Harnett W. ES-62, a therapeutic anti-inflammatory agent evolved by the filarial nematode Acanthocheilonema viteae. Mol Biochem Parasitol. 2014;194(1-2):1-8. doi:10.1016/j.molbiopara.2014.03.003.

84. Perona-Wright G, Jenkins SJ, MacDonald AS. Dendritic cell activation and function in response to Schistosoma mansoni. Int $J$ Parasitol. 2006;36(6):711-721. doi:10.1016/j.jpara.2006.02.003.

85. Bhargava P, Li C, Stanya KJ, et al. Immunomodulatory glycan LNFPIII alleviates hepatosteatosis and insulin resistance through direct and indirect control of metabolic pathways. Nat Med. 2012;18(11):1665-1672. doi:10.1038/nm.2962.

86. Holland MJ, Harcus YM, Riches PL, Maizels RM. Proteins secreted by the parasitic nematode Nippostrongylus brasiliensis act as adjuvants for Th2 responses. Eur $J$ Immunol. 2000;30(7):1977-1987. doi:10.1002/1521-4141(200007)30:7<1977::AIDIMMU1977>3.0.CO;2-3.

87. Mottram JC, Brooks DR, Coombs GH. Roles of cysteine proteinases of trypanosomes and Leishmania in host-parasite interactions. Curr Opin Microbiol. 1998;1(4):455-460. doi:10.1016/S1369-5274(98)80065-9.

88. Brooks DR, Tetley L, Coombs GH, Mottram JC. Processing and trafficking of cysteine proteases in Leishmania mexicana. J Cell Sci. 2000;113 ( Pt 22):4035-4041.

89. Furmonaviciene R, Sewell HF. Comparative molecular modelling identifies a common putative IgE epitope on cysteine protease allergens of diverse sources. Clin Ldots. 2000.

90. Libby P. Inflammation in atherosclerosis. Nature. 2002;420(6917):868-874. doi:10.1038/nature01323.

91. Wolfs IMJ, Stöger JL, Goossens P, et al. Reprogramming macrophages to an antiinflammatory phenotype by helminth antigens reduces murine atherosclerosis. FASEB J. 2014;28(1):288-299. doi:10.1096/fj.13-235911.

92. Mathieu P, Pibarot P, Després J-P. Metabolic Syndrome: The Danger Signal in Atherosclerosis. Vasc Health Risk Manag. 2006;2(3):285-302.

93. La Flamme AC, Harvie M, Kenwright $D$, et al. Chronic exposure to schistosome eggs reduces serum cholesterol but has no effect on atherosclerotic lesion development. Parasite Immunol. 2007;29(5):259-266. doi:10.1111/j.1365-3024.2007.00942.x.

94. Mclnnes IB, Leung BP, Harnett M, Gracie JA, Liew FY, Harnett W. A Novel Therapeutic Approach Targeting Articular Inflammation Using the Filarial NematodeDerived Phosphorylcholine-Containing Glycoprotein ES-62. J Immunol. 2003;171(4):2127-2133. doi:10.4049/jimmunol.171.4.2127.

This article is protected by copyright. All rights reserved. 
95. Pineda MA, McGrath MA, Smith PC, et al. The parasitic helminth product ES-62 suppresses pathogenesis in collagen-induced arthritis by targeting the interleukin-17producing cellular network at multiple sites. Arthritis Rheum. 2012;64(10):3168-3178. doi:10.1002/art.34581.

96. Rodgers DT, McGrath MA, Pineda MA, et al. The parasitic worm product ES-62 targets myeloid differentiation factor 88-dependent effector mechanisms to suppress antinuclear antibody production and proteinuria in MRL/lpr mice. Arthritis Rheumatol Hoboken NJ. 2015;67(4):1023-1035. doi:10.1002/art.39004.

97. Aprahamian T, Rifkin I, Bonegio R, et al. Impaired Clearance of Apoptotic Cells Promotes Synergy between Atherogenesis and Autoimmune Disease. J Exp Med. 2004;199(8):1121-1131. doi:10.1084/jem.20031557.

98. Aprahamian TR, Zhong X, Amir S, et al. The immunomodulatory parasitic worm product ES-62 reduces lupus-associated accelerated atherosclerosis in a mouse model. Int J Parasitol. 2015;45(4):203-207. doi:10.1016/j.jpara.2014.12.006.

99. Saeij JPJ, Coller S, Boyle JP, Jerome ME, White MW, Boothroyd JC. Toxoplasma coopts host gene expression by injection of a polymorphic kinase homologue. Nature. 2006;445(7125):324-327.

100. Butcher BA, Fox BA, Rommereim LM, et al. Toxoplasma gondii Rhoptry Kinase ROP16 Activates STAT3 and STAT6 Resulting in Cytokine Inhibition and Arginase-1Dependent Growth Control. PLoS Pathog. 2011;7(9):e1002236.

101. Jensen KDC, Wang Y, Wojno EDT, et al. Toxoplasma Polymorphic Effectors Determine Macrophage Polarization and Intestinal Inflammation. Cell Host Microbe. $2011 ; 9(6): 472-483$.

102. Son ES, Song KJ, Shin JC, Nam HW. Molecular cloning and characterization of peroxiredoxin from Toxoplasma gondii. Korean J Parasitol. 2001;39(2):133-141.

103. Marshall ES, Elshekiha HM, Hakimi M-A, Flynn RJ. Toxoplasma gondii peroxiredoxin promotes altered macrophage function, caspase-1-dependent IL-1 $\beta$ secretion enhances parasite replication. Vet Res. 2011;42:80.

104. Flynn RJ, Irwin JA, Olivier M, Sekiya M, Dalton JP, Mulcahy G. Alternative activation of ruminant macrophages by Fasciola hepatica. Vet Immunol Immunopathol. 2007; 120(1-2):31-40.

105. Donnelly S, Stack CM, O'Neill SM, Sayed AA, Williams DL, Dalton JP. Helminth 2-Cys peroxiredoxin drives Th2 responses through a mechanism involving alternatively activated macrophages. FASEB J. 2008;22(11):4022-4032.

106. Goodridge HS, Wilson EH, Harnett W, Campbell CC, Harnett MM, Liew FY. Modulation of macrophage cytokine production by ES-62, a secreted product of the filarial nematode Acanthocheilonema viteae. J Immunol Baltim Md 1950. 2001;167(2):940-945.

107. Ahmed UK, Maller NC, lqbal AJ, Al-Riyami L, Harnett W, Raynes JG. The Carbohydrate-linked Phosphorylcholine of the Parasitic Nematode Product ES-62 Modulates Complement Activation. J Biol Chem. 2016;291(22):11939-11953. doi:10.1074/jbc.M115.702746.

This article is protected by copyright. All rights reserved. 
108. Trial J, Cieslik KA, Entman ML. Phosphocholine-containing ligands direct CRP induction of M2 macrophage polarization independent of $\mathrm{T}$ cell polarization: Implication for chronic inflammatory states. Immun Inflamm Dis. June 2016:n/a-n/a. doi:10.1002/iid3.112.

109. Alvarado R, O'Brien B, Tanaka A, Dalton JP, Donnelly S. A parasitic helminth-derived peptide that targets the macrophage lysosome is a novel therapeutic option for autoimmune disease. Immunobiology. 2015;220(2):262-269. doi:10.1016/j.imbio.2014.11.008.

110. Rzepecka J, Pineda MA, Al-Riyami L, et al. Prophylactic and therapeutic treatment with a synthetic analogue of a parasitic worm product prevents experimental arthritis and inhibits IL-1 $\beta$ production via NRF2-mediated counter-regulation of the inflammasome. J Autoimmun. 2015;60:59-73. doi:10.1016/j.jaut.2015.04.005.

111. Shio MT, Christian JG, Jung JY, Chang K-P, Olivier M. PKC/ROS-Mediated NLRP3 Inflammasome Activation Is Attenuated by Leishmania Zinc-Metalloprotease during Infection. PLoS Negl Trop Dis. 2015;9(6):e0003868.

112. Jin C, Flavell RA. Innate sensors of pathogen and stress: Linking inflammation to obesity. J Allergy Clin Immunol. 2013;132(2):287-294. doi:10.1016/j.jaci.2013.06.022.

113. Rzepecka J, Siebeke I, Coltherd JC, et al. The helminth product, ES-62, protects against airway inflammation by resetting the Th cell phenotype. Int $J$ Parasitol. 2013;43(3-4):211-223. doi:10.1016/j.ijpara.2012.12.001.

114. Coltherd JC, Rodgers DT, Lawrie RE, et al. The parasitic worm-derived immunomodulator, ES-62 and its drug-like small molecule analogues exhibit therapeutic potential in a model of chronic asthma. Sci Rep. 2016;6:19224. doi:10.1038/srep19224.

115. Al-Riyami L, Rodgers DT, Rzepecka J, et al. Protective effect of small molecule analogues of the Acanthocheilonema viteae secreted product ES-62 on oxazoloneinduced ear inflammation. Exp Parasitol. 2015;158:18-22. doi:10.1016/j.exppara.2015.03.025.

116. Harn DA, McDonald J, Atochina O, Da'dara AA. Modulation of host immune responses by helminth glycans. Immunol Rev. 2009;230(1):247-257. doi:10.1111/j.1600-065X.2009.00799.x.

117. van Liempt $E$, van Vliet SJ, Engering $A$, et al. Schistosoma mansoni soluble egg antigens are internalized by human dendritic cells through multiple C-type lectins and suppress TLR-induced dendritic cell activation. Mol Immunol. 2007;44(10):2605-2615. doi:10.1016/j.molimm.2006.12.012.

118. Zheng $\mathrm{X}, \mathrm{Hu} \mathrm{X}$, Zhou G, et al. Soluble egg antigen from Schistosoma japonicum modulates the progression of chronic progressive experimental autoimmune encephalomyelitis via Th2-shift response. J Neuroimmunol. 2008;194(1):107-114. doi:10.1016/j.jneuroim.2007.12.001.

119. Zaccone $\mathrm{P}$, Fehérvári $Z$, Jones FM, et al. Schistosoma mansoni antigens modulate the activity of the innate immune response and prevent onset of type 1 diabetes. Eur $J$ Immunol. 2003;33(5):1439-1449. doi:10.1002/eji.200323910.

This article is protected by copyright. All rights reserved. 
120. Thomas PG, Carter MR, Atochina O, et al. Maturation of Dendritic Cell 2 Phenotype by a Helminth Glycan Uses a Toll-Like Receptor 4-Dependent Mechanism. J Immunol. 2003;171(11):5837-5841. doi:10.4049/jimmunol.171.11.5837.

121. Atochina O, Harn D. Prevention of psoriasis-like lesions development in fsn/fsn mice by helminth glycans. Exp Dermatol. 2006;15(6):461-468. doi:10.1111/j.16000625.2006.00431.x.

122. Falcón C, Carranza F, Martínez FF, et al. Excretory-secretory products (ESP) from Fasciola hepatica induce tolerogenic properties in myeloid dendritic cells. Vet Immunol Immunopathol. 2010;137(1-2):36-46. doi:10.1016/j.vetimm.2010.04.007.

123. Donnelly S, O'Neill SM, Sekiya M, Mulcahy G, Dalton JP. Thioredoxin Peroxidase Secreted by Fasciola hepatica Induces the Alternative Activation of Macrophages. Infect Immun. 2005;73(1):166-173. doi:10.1128/IAI.73.1.166-173.2005.

124. Lund ME, O'Brien BA, Hutchinson AT, et al. Secreted Proteins from the Helminth Fasciola hepatica Inhibit the Initiation of Autoreactive T Cell Responses and Prevent Diabetes in the NOD Mouse. PLOS ONE. 2014;9(1). doi:10.1371/journal.pone.0086289.

125. Dowling DJ, Hamilton CM, Donnelly S, et al. Major Secretory Antigens of the Helminth Fasciola hepatica Activate a Suppressive Dendritic Cell Phenotype That Attenuates Th17 Cells but Fails To Activate Th2 Immune Responses. Infect Immun. 2010;78(2):793-801. doi:10.1128/IAI.00573-09.

126. Alvarado R, To J, Lund ME, et al. The immune modulatory peptide FhHDM-1 secreted by the helminth Fasciola hepatica prevents NLRP3 inflammasome activation by inhibiting endolysosomal acidification in macrophages. FASEB J Off Publ Fed Am Soc Exp Biol. September 2016. doi:10.1096/fj.201500093R.

127. Trujillo-Vargas CM, Werner-Klein M, Wohlleben G, et al. Helminth-derived products inhibit the development of allergic responses in mice. Am J Respir Crit Care Med. 2007;175(4):336-344. doi:10.1164/rccm.200601-054OC.

128. Balic A, Harcus $Y$, Holland MJ, Maizels RM. Selective maturation of dendritic cells by Nippostrongylus brasiliensis-secreted proteins drives Th2 immune responses. Eur $J$ Immunol. 2004;34(11):3047-3059. doi:10.1002/eji.200425167.

This article is protected by copyright. All rights reserved. 
Figure Legends

Figure 1: The role of PI3K/Akt, mTORC1, mTORC2, and the NLRP3 inflammasome in the development of metabolic syndrome. A schematic detailing the key signalling molecules and pathways activated/supressed during nutrient excess, insulin resistance and associated chronic inflammation.

Figure 2: Parasitic ES products are able to influence a range of signalling pathways such as PI3K/Akt and the inflammasome, as well as biasing immune system cells towards a type 2 phenotype, both of which suggest they may be able to provide protection against MetS.

Table 1: The mechanisms of action of some of the best characterised parasite-derived excretory-secretory products on the immune system and in murine disease models is summarised.

This article is protected by copyright. All rights reserved. 


\begin{tabular}{|c|c|c|c|}
\hline \begin{tabular}{|c|} 
Parasite \\
excretory- \\
secretory \\
product \\
\end{tabular} & Immune responses affected & Animal disease model & References \\
\hline A. viteae ES-62 & $\begin{array}{c}\text { Downregulates MyD88 to subvert TLR- } \\
\text { mediated activation of macrophages, DCs and } \\
\text { mast cells in a TLR4-dependent manner; } \\
\text { resets macrophage and TH1/TH2/TH17 } \\
\text { homeostasis; inhibits B2 cell activation and } \\
\text { induces IL-10-secreting B1 cells and various } \\
\text { Breg populations }\end{array}$ & $\begin{array}{l}\text { Collagen-induced arthritis (CIA); } \\
\text { ovalbumin-induced airway } \\
\text { hypersensitivity; oxazolone-induced } \\
\text { contact sensitivity, MRL/lpr model of } \\
\text { SLE, Gld.ApoE }{ }^{-/-} \text {model of lupus- } \\
\text { associated accelerated atherosclerosis }\end{array}$ & $\begin{array}{c}12,83,95,96,98,113, \\
131,14,141,15\end{array}$ \\
\hline S. mansoni SEA & $\begin{array}{c}\text { Priming of DCs towards a TH } 2 \text { phenotype, } \\
\text { induction of } \mathrm{TH} 2 \text { cells in vivo, induction of } \\
\text { Tregs }\end{array}$ & $\begin{array}{c}\text { Experimental Autoimmune } \\
\text { Encephalomyelitis (EAE); Type } 1 \\
\text { Diabetes (T1D) in non-obese diabetic } \\
\text { (NOD) mice; CIA; glucose tolerance in } \\
\text { HFD-fed mice; cholesterol-driven } \\
\text { model of atherosclerosis }\end{array}$ & $18,85,116-119$ \\
\hline S. mansoni LNFPIII & $\begin{array}{c}\text { Induction of AAM phenotype; priming of } \\
\text { DCs towards a TH2 phenotype }\end{array}$ & $\begin{array}{l}\text { glucose tolerance in HFD-fed mice; } \\
\text { psoriasis; T1D; EAE }\end{array}$ & $20,85,116,120,121$ \\
\hline F. hepatica ES & $\begin{array}{l}\text { Priming of DCs to induce } \mathrm{TH} 2 \text { and Treg } \\
\text { responses; induction of AAMs; inhibition of } \\
\text { TH17 responses in vivo }\end{array}$ & T1D in NOD mice; CIA & $24,122-125$ \\
\hline F. hepatica HDM-1 & $\begin{array}{l}\text { induction of AAM; inhibition of NLRP3 } \\
\text { inflammasome activation in macrophages }\end{array}$ & $\begin{array}{c}\text { murine models of T1D and multiple } \\
\text { sclerosis }\end{array}$ & $25,124,126$ \\
\hline $\begin{array}{c}F . \text { hepatica } \\
\text { peroxiredoxin }\end{array}$ & Induction of AAM & not tested & 04105 \\
\hline N. brasiliensis ES & Induction of $\mathrm{TH} 2$ cells in vivo via DC priming & allergic lung inflammation & $27,86,127,128$ \\
\hline H. polygyrus ES & $\begin{array}{l}\text { Inhibition of TH1 responses; inhibition of } \\
\text { macrophage NO production; inhibition of } \\
\text { PAMP-mediated DC responses }\end{array}$ & not tested & 50,51 \\
\hline L. mexicana CPB2.8 & $\begin{array}{c}\text { Induction of TH2 response in vivo, induction } \\
\text { of } \operatorname{IgE}\end{array}$ & not tested & 58,59 \\
\hline $\begin{array}{c}\text { T. gondii } \text { Rhoptry } \\
\text { proteins }\end{array}$ & $\begin{array}{l}\text { Suppression of IL-1; enhanced arginase-1 in } \\
\text { macrophages and fibroblasts }\end{array}$ & not tested & 100,101 \\
\hline $\begin{array}{l}T . \text { gondii } \\
\text { peroxiredoxin }\end{array}$ & $\begin{array}{l}\text { Induction of AAM; stimulation of IL-10; } \\
\text { inhibition of macrophage ROS and IL-1 } \\
\text { production via inhibition of NLRP3 } \\
\text { inflammasome activation }\end{array}$ & not tested & 102,103 \\
\hline
\end{tabular}

This article is protected by copyright. All rights reserved. 

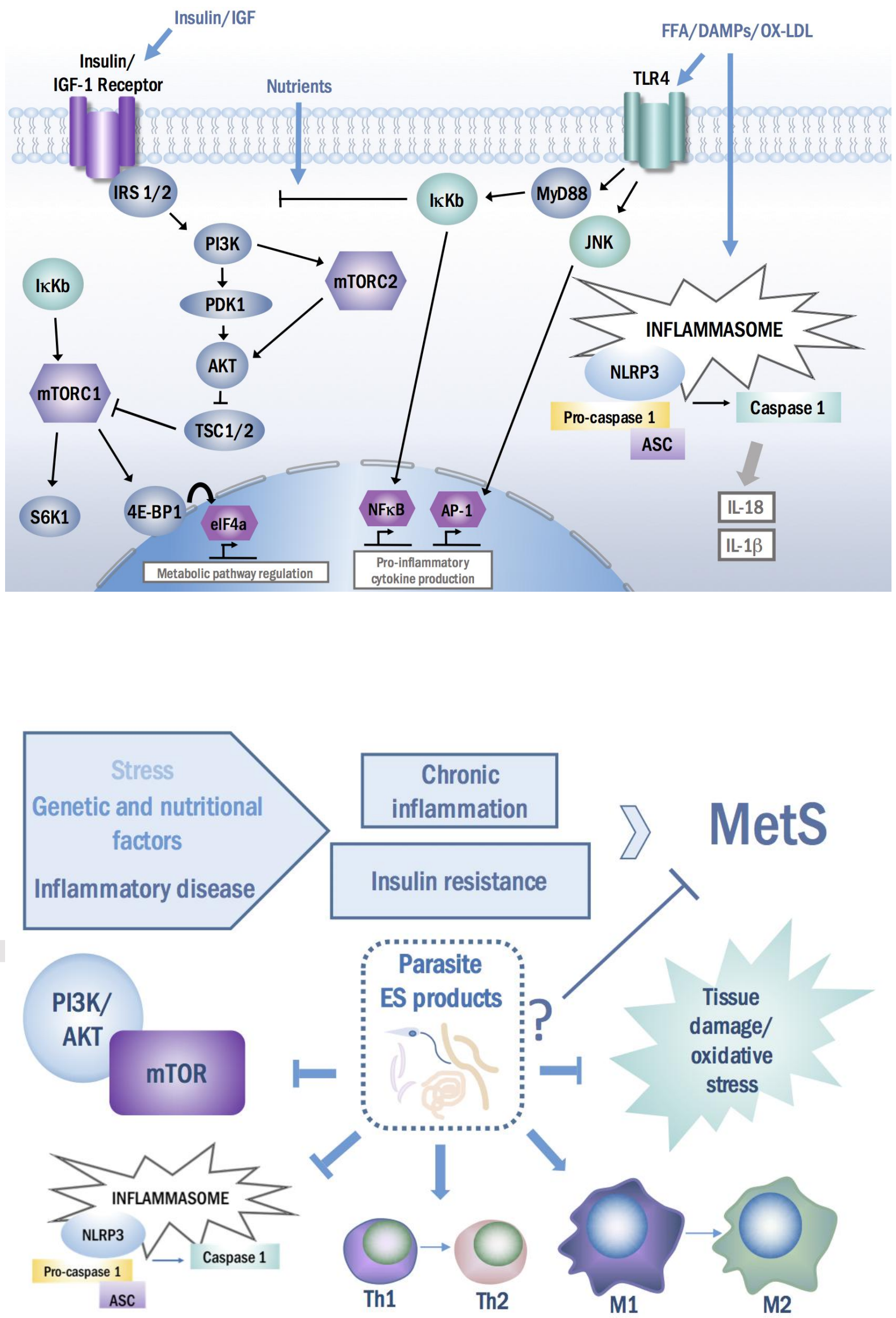

This article is protected by copyright. All rights reserved. 